\title{
Students' Use of Resources in a Challenge-Based Learning Context Involving Mathematics
}

\author{
Birgit Pepin $^{1}$ (1) $\cdot$ Zeger-jan Kock $^{1}$ (1)
}

Accepted: 2 February 2021/ Published online: 10 March 2021

(C) The Author(s) 2021

\begin{abstract}
In this study we use a case study approach to investigate what kinds of resources were self-reported to have been selected by students working on their Challenge-Based bachelor end projects, and how they used and orchestrated these resources. In a previous study, we had explored students' use of resources and their Actual Student Study Paths in Calculus and Linear Algebra courses (Pepin and Kock 2019); in this study we turned to students working on their Challenge-Based bachelor end projects. Results show that the students working on Challenge-Based projects used resources outside the realm of curriculum resources offered to them in traditional courses, and the Actual Student Study Paths were iterative. We contend that 'linear' study paths (found e.g. in traditionally taught Linear Algebra courses) appeared to have been beneficial for students for studying particular mathematical content, which they needed for solving open challenges. In the Challenge-Based projects, the crucial resource emerged to be the tutor. We claim that this has implications for the introduction of a more ChallengeBased curriculum, where such projects would be the norm, both in terms of the professionalization of university teachers (who coach students through such projects), and for the education of students who opt for such projects: teachers have to be supported to develop as appropriate coaches in such complex environments; students have to become self-directed learners, and need to be supported with challenged-based trained coaches and teachers, in addition to be provided with suitable curricular, technological, and social resources.
\end{abstract}

Keywords Resources - Student use of resources - Actual student study path $\cdot$ Challengebased education

Birgit Pepin

b.e.u.pepin@tue.nl

1 Eindhoven School of Education, Eindhoven University of Technology, Eindhoven, Netherlands 


\section{Introduction}

At university, students use, sequence, and align different resources in order to study mathematics. Among others, these resources include textbooks, Digital Learning Environments, interactions with peers and tutors, software and YouTube videos. In traditional lecture - tutor group university mathematics courses, students organize, sequence and align their work with resources in ways that depend, among others, on the course organization and their preferred ways of studying. In an earlier study, we have used the term Actual Student Study Paths (ASSP) for the orchestration of resources in such learning environments (Pepin and Kock 2019). However, universities of technology tend to move towards more Challenge-Based (CB) education, where interdisciplinary groups of students work on authentic engineering tasks (Malmqvist et al. 2015). It has been argued (e.g. Dahl 2018) that mathematics fits into CB learning approaches, although it is not clear what kinds of resources and support would benefit students in such learning environments.

In $\mathrm{CB}$ projects related to engineering, students might need particular mathematical knowledge, but they have to develop their own study strategies to identify what knowledge they need, how to acquire that knowledge, and subsequently how to use it in their projects. We expect that student needs regarding the selection and use of resources in a CB project is likely to be different from those in a traditional lecture - tutor group environment. Knowledge on how students use resources and how they develop their ASSPs in CB projects might help university tutors and teachers to guide students effectively to progress with their learning and with their projects. Inglis et al. (2011) suggested that students might need explicit guidance on how to combine the use of various resources into an effective learning strategy.

We note that relatively little research is available on how students actually orchestrate the resources in order to study mathematics. In this study, we consider the use of resources from a student perspective in two cases of $\mathrm{CB}$ projects; these were Bachelor End Projects at a university of technology in the Netherlands. We aim to extend the notion of ASSP to CB education, and so to contribute to the understanding of how the use of resources shapes and supports students' study processes.

We ask the following research questions:

(1) What kinds of resources were selected by the students, and how did they use these resources, in their Challenge-Based projects?

(2) What were their Actual Student Study Paths, and what were the implications of such paths in terms of providing access to suitable resources for Challenge-Based education?

First, we outline the theoretical frames we have used: resources, Challenge-Based education, and Actual Student Study Paths. Second, we describe in more detail the context in which the study took place. Third, we describe the research methods we used. Fourth, we present the results pertaining to the two cases. Fifth, we discuss the results of this study, also compared to results of the previous study, and present our conclusions. 


\section{Theoretical Frames}

In this study we use the theoretical frames of (a) Resources, (b) Actual Student Study Path (ASSP), and (c) Challenge-Based (CB) education, for our purpose of identifying students' use and orchestration of resources and their study paths in CB projects.

\section{The Lens of resources}

In previous studies the notion of 'resource' has been used (e.g. Pepin and Gueudet 2018). In this study, following Pepin and Gueudet $(2018,2014)$ we distinguish between (a) curriculum resources (material, text, or digital); (b) social resources; and (c) cognitive resources. In the context of this study we have also added (d) general resources as an additional category; these are the resources students choose beyond the ones proposed by the university. Table 1 shows descriptions and examples of these categories.

Several studies lean on this notion to study what kinds of resources and materials students have access to, use, and orchestrate for their study of mathematics and engineering (e.g. Anastasakis et al. 2017; Gueudet and Pepin 2018; Pepin and Kock 2019). We assume that the ways university students study mathematics are influenced by the use of the various resources at their disposal. By 'use of resources' we denote which resources students choose amongst the many on offer and for what purpose (e.g. revision); the ways they align, sequence and orchestrate them (e.g. first lecture, then checking the textbook); which ones seem central to achieve particular study goals (e.g. for weekly course work, for examinations). However, we do not address how students interact with particular resources to learn particular mathematical topic areas.

Studies have been conducted on the use of particular curriculum resources. For example, in a review study Biza et al. (2016) have described the opportunities afforded by introductory university mathematics textbooks, and their actual use by students in traditional lecture-tutor group courses. The use of curriculum resources has been

Table 1 Categories of resources and examples, based on (Pepin and Gueudet 2018). For this study the category General Resources was added

\begin{tabular}{|c|c|c|}
\hline Resource category & Description & Examples \\
\hline Curriculum & $\begin{array}{l}\text { All the resources that are } \\
\text { developed and used by teachers } \\
\text { and students in their interaction } \\
\text { with mathematics for teaching } \\
\text { and learning, inside and outside } \\
\text { the classroom. These resources } \\
\text { are intended to be aligned with } \\
\text { the mathematics curriculum. }\end{array}$ & $\begin{array}{l}\text { Text resources: textbooks, teacher } \\
\text { curricular guidelines, } \\
\text { worksheets. } \\
\text { Other material resources: } \\
\text { manipulatives, calculators. } \\
\text { Web based resources: digital } \\
\text { learning environment. } \\
\text { Digital resources: Matlab }\end{array}$ \\
\hline Social & $\begin{array}{l}\text { Formal or casual human } \\
\text { interactions. }\end{array}$ & $\begin{array}{l}\text { Conversations with tutors, peers } \\
\text { and friends }\end{array}$ \\
\hline Cognitive & $\begin{array}{l}\text { Mathematical frameworks and } \\
\text { concepts students work with. }\end{array}$ & $\begin{array}{l}\text { The concept and techniques of } \\
\text { differentiation. }\end{array}$ \\
\hline General & $\begin{array}{l}\text { Non-curricular material resources } \\
\text { mobilized by students. }\end{array}$ & $\begin{array}{l}\text { Wikipedia, Wolfram Alpha, } \\
\text { YouTube }\end{array}$ \\
\hline
\end{tabular}


studied by Inglis et al. (2011), who investigated ways in which undergraduates used optional resources in a typical blended learning environment. They were particularly interested in how students blended the resources during a multivariate calculus course: how often students attended live face-to-face lectures, accessed online recorded lectures, and visited a mathematics learning support center. They claimed that "the general strategy a student adopted was related to their academic achievement, both in the multivariate calculus course, and in their degree program more widely" (p. 490). For example, those students who often accessed online lectures had lower attainment than those who often attended live lectures or the support center.

There are relatively few studies that have included the selection and use of resources across multiple categories. One of those is the study by Anastasakis et al. (2017), who investigated the different types of resources that a cohort of second-year engineering undergraduates used. Their results showed that student practices were dominated by curriculum resources provided by their university, although to some extent students used general resources they had found themselves. The students in their sample chose resources mainly because these enabled them to pursue their examination-driven goals.

Generally, in CB projects students do not receive a pre-defined set of curriculum resources and have to develop their own selection and use strategies. That is, they have to identify what they need to learn for their work on the project, select and use resources accordingly, and develop the CB project based on the insights they gained. Hence, we expect that student needs regarding the selection and use of resources in a $\mathrm{CB}$ project differ from those in traditional lecture-tutor group courses.

\section{Actual Student Study Paths (ASSP)}

The concept of learning trajectory has a long history. It is associated with the necessity to resource students' thinking in instruction or coaching, and is of critical importance for teachers, in particular if one takes seriously the view that "one must start where the student is" (Ausubel 1963, p5).

The research literature in mathematics and science education shows many different terms and concepts linking to student learning trajectories, often associated with instructional theory and curriculum design. Simon (1995) introduced the term hypothetical learning trajectory to capture the result of a process in which a teacher posits a conjecture regarding her students' current understanding of a targeted concept and then develops learning activities that she thinks will support them in constructing more sophisticated ways of reasoning toward a particular learning goal. He proposed that the hypothetical learning trajectory should include "the learning goals, the learning activities, and the thinking and learning in which students might engage" (p.133). Building on this work, Simon and Tzur (2004) described a learning trajectory as a combination of a developmental progression and an instructional sequence. In their more elaborated definition of a learning trajectory, Deane et al. (2013) recognized not only this developmental progression, but also the reasons for this progression and the possibility that individual students' paths may differ:

... a description of qualitative change in a student's level of sophistication for a key concept, process, strategy, practice, or habit of mind. Change in student standing on such a progression may be due to a variety of factors, including maturation and instruction. Each progression is presumed to be a model-i.e. to 
hold for most, but not all students. Finally, it is provisional, subject to empirical verification and theoretical challenge ... (Deane et al. 2013, para. 1, cited in Graf and van Rijn 2016, p.166)

It is noteworthy that whilst learning trajectories may be packaged as a set of descriptions of levels and associated tasks and curriculum resources, Lehrer and Schauble (2015) claim that learning trajectories are not context-free accounts of learning. They contend that, grounded in classroom studies, learning trajectories more broadly refer to "the educational experiences that support the developing learner, and these educational experiences are delineated in the learning progression model both as principles that guide educational design and as mechanisms that account for learning" (p.433).

Whilst recognizing the work on learning trajectories, using the lens of resources we regarded it necessary (a) to investigate students' own perceptions of how they manage their studying; and (b) to coin a term that linked to the observation of patterns of how students perceived their selection, use, sequencing and alignment of resources. When investigating students' study paths, we therefore considered: (1) the orchestration of resources, not of tasks or activities; (2) the students' perspective, that is, how they actually orchestrated the resources for their own learning, and how they gave meaning to these self-created paths. In an earlier study we called these Actual Student Study Paths (ASSP- Pepin and Kock 2019): students' self-reported study paths, perceived in terms of their resource selection and organization. In that first study we outlined selected study paths for the first-year courses of Calculus and Linear Algebra. In brief, we found that in the Calculus and Linear Algebra courses a number of resources had been suggested as curriculum resources. In the case of Linear Algebra these included, well-defined and aligned, a reader, lectures and tutor hours which were proposed and provided in a study path for the students. In the case of Calculus, there was less alignment of the curriculum resources and the students created their own ASSPs. However, in both cases the examinations and the sequence of weekly lectures and homework assignments had an impact on the students' ASSPs.

\section{Challenge-Based (CB) Education}

$\mathrm{CB}$ education is considered a student-centered learning and teaching approach. In $\mathrm{CB}$ education students are actively involved in choosing and developing their own learning trajectory. CB learning is related to but distinguishable from other student-centered forms of learning, such as problem-based learning. CB learning is said to be different from problembased learning, in that instead of presenting students with a problem to solve, $\mathrm{CB}$ learning offers general concepts, or grand challenges, from which the students themselves identify and determine a particular problem they will address. In addition, in CB projects students typically design and create a prototype solution to the problem in multidisciplinary groups (Malmqvist et al. 2015).

CB learning challenges are often connected to big issues that critically need to be addressed to ensure the sustainability of human societies during the coming century (e.g. National Academy of Engineering 2017). As participants determine where a problem lies, how a solution might be affected, and how technology can be leveraged to accomplish a workable result, they learn the value of different perspectives, critical thinking and reflection. In this way, $\mathrm{CB}$ learning experiences potentially engage students in ways of thinking and 
learning authentic to the engineering profession, and they contribute to deeper learning and meaning making than traditional lecture-based courses (Case and Marshall 2004). Moreover, the CB learning experiences can be seen as a further step in enhancing student participation in conceiving and defining their own learning trajectories, as well as a step towards integrating sustainability in engineering education (Enelund et al. 2013).

Often mathematics is the content area where students struggle to see its value, until they arrive at an engineering challenge that typically cannot be solved without mathematics. Therefore, one way to stimulate students to appreciate the value of mathematics is to frame the mathematics learning around engaging, authentic problems related to a 'real' challenge (Rasmussen and Kwon 2007).

$\mathrm{CB}$ education changes the roles of both the teacher and the student. For students, the emphasis is on becoming a more self-regulated learner. Due to the open-ended complex and scientific nature of the examined research question, the teacher's role changes from a knowledge provider to becoming a coach, co-experimenter and even a partner in learning. Student work is guided by external partners ("challenge owners" - these are people/managers from industry who have proposed the grand challenge and they are stakeholders in the solution of the challenge), tutors and coaches. With these parties involved, collaboration in the team of educators and stakeholders becomes more important.

In a curriculum that places CB learning at its center, it is necessary to facilitate diverse and personalized learning paths. Students need to access and develop knowledge in an agile way, at the moment it is required in their $\mathrm{CB}$ projects. Therefore, modularization and digitalization of resources are essential.

CB learning experiences are typically placed in a societal context, and they have benefited from and driven the emergence of a new kind of learning environment, the 'innovation' labs, or Maker spaces. In a survey paper, Gryszkiewicz et al. (2016) define an (open) innovation lab as a "semi-autonomous organization that engages diverse participants - on a long-term basis - in open collaboration for the purpose of creating, elaborating, and prototyping radical solutions to open-ended systemic challenges" (p.77/78). These learning environments aim not only to foster student learning, but also to promote collaboration between university, business and the public sector. Students play a key role, in problem-solving, and in driving a collaborative, multi-perspective dialogue on defining the problem to be solved. In addition to a physical arena, the innovation labs typically provide a set of methods for addressing a societal challenge, from problem identification to solution concept (Hassan 2014).

\section{The Study}

In this section we explain the context of the study; we outline the methodological approach we used for our study, and the data collection strategies, which are underpinned and structured by curriculum theory.

\section{The Context}

The university where this study took place claims that its aim is to educate the 'engineers of the future', that is engineers who have a deep understanding of their 
discipline, keep their knowledge and skills up to date, and are able to work on complex systems in multidisciplinary settings and teams. The university has formulated a vision for education in the year 2030, and in this vision CB education plays an important role (Deans Bachelor College and Graduate School 2020). Presently, the university is taking steps to create a growing number of opportunities for student learning based on the principles of $\mathrm{CB}$ education, with the view of identifying promising practices (both in terms of teaching and learning) for a reformed curriculum based on $\mathrm{CB}$ education.

One of the CB learning opportunities has been created in the Innovation Space (ISan innovation lab, as described earlier): students could choose to conduct their bachelor end project in the IS. This means that groups of 4-5 bachelor students worked together in multi-disciplinary teams (e.g. industrial design, mechanical engineering, innovation sciences) on a challenge, set by a stakeholder from outside the university. The projects were unstructured but the students had to fulfill Bachelor End Project requirements of their respective disciplines and departments. This setup provided students with opportunities to investigate and analyze an authentic situation and to develop a (prototype) solution. Different projects included various degrees of mathematics. No particular resources were stipulated or provided, except that each group had a coach and a tutor (student-assistant) from IS and an outside stakeholder, who supported the collaboration process and steered the projects. Moreover, each student had an academic coach from his/her engineering department, who supported the student regarding disciplinary content. Earlier, students had followed "traditional" mathematics courses (e.g. Calculus, Linear Algebra), where they were provided with particular curriculum resources (Pepin and Kock 2019).

\section{A Curriculum Perspective}

As this study has been conducted at a time of curriculum change, from traditional lecture-tutorial driven to $\mathrm{CB}$ education, we use the curriculum (development) literature as an analytical frame to structure our data collection.

The curriculum can be represented in different forms. Curriculum research typically distinguishes between the three levels (intended, enacted, attained) which are more refined in Table 2.

The division into six representations is especially useful for an analysis of the processes (and the outcomes) of curriculum reforms. This distinction of forms emphasizes the different layers of the curriculum and demonstrates the often-substantial discrepancies between the various forms, and where they overlap. For us, they were also useful to identify at which level we could collect the necessary data.

\section{Methods}

In order to find out about our students' use and interaction with resources, we used a case study approach. In the present study we explored six students' use of resources for their Challenge-Based Bachelor End Projects (CBBEP), placed in the third year of the three-year bachelor curriculum. Three students worked in the Parkinson Project group, and three worked in the Resonant Garden group. The students had different majors. Each groups of students collaboratively worked on a prototype solution to the problem 
Table 2 Typology of curriculum representations (Thijs and Van den Akker 2009, p.10)

\begin{tabular}{lll}
\hline Level & Representation & Description \\
\hline Intended & Ideal & $\begin{array}{c}\text { Vision (rationale or basic philosophy underlying a } \\
\text { curriculum): e.g. CB education as outlined in } \\
\text { university education strategy document }\end{array}$ \\
& Formal & $\begin{array}{c}\text { Intentions as specified in curriculum documents and } \\
\text { materials: e.g. curriculum resources used }\end{array}$ \\
& Perceived & (textbooks; study guide; other resources) \\
& Curriculum as interpreted by its users (especially \\
Enacted & teachers) \\
& Actual process of teaching and learning (also: \\
& curriculum-in-action) \\
Attained & Learning experiences as perceived by learners \\
& Resulting learning outcomes of learners (e.g. \\
& examinations; bachelor end reports)
\end{tabular}

they had derived from the challenge. However, within that context, students worked on tasks related to their majors, so that they could fulfill de BEP requirements of their departments (see Tables 3 and 4).

In terms of data collection strategies, we aligned our strategies with the three curriculum levels (intended, enacted, attained curriculum):

(1) at the level of the intended curriculum:

Examination of documents and curriculum materials provided by the university and lecturers for the students: e.g. syllabi, study guides, resources provided by the different engineering departments. This was mainly done to understand the contexts in which students were working in the IS as compared to their 'home departments'.

(2) at the level of the enacted curriculum:

a. Selected observations in the IS environment included observations of mid-term and end-of-project presentations; observations of student working places in the IS labs; observations of tutor meetings where the projects were discussed (including assessment of projects).

b. Individual and focus group interviews with four student groups working on CBBEPs. In two of these projects mathematical knowledge was important for the students to understand, model, or solve the problem. In this study we focus on these two groups (altogether 6 students of these groups participated in the interviews). The interviews were conducted in English, which was a second language for most students.

c. During the interviews, students were asked to draw Schematic Representation of their Resource System (SRRS - see Pepin et al. 2017b), that is, to draw which resources they had identified, accessed and used, and how they had aligned them in the progress of the project. Students were free to choose the 
format of their drawing. We used the drawing task to give students time to think about the particular resources they had used, and the connection between the resources and their project. At a later stage of the interview students were asked to explain their resource use based on their SRRSs. We specifically asked the students about the mathematical resources they used. The connections made in the SRRSs in combination with the explanations, helped the researchers to identify the students' study paths (ASSPs). Thus, the SRRSs served as a methodological tool, to focus the students' attention on the resources and their use, and to help the researchers better understand what the students explained in the interviews.

d. We conducted informal conversations with course leaders, in order to understand the context of the IS and the ways students and tutors were expected to work.

(3) At the level of the attained curriculum:

a. Bachelor end project reports were analyzed, in order to get a better understanding of the role of mathematics in the projects and of the learning outcomes as reported by the students.

b. During the group interviews, students were probed for their learning experiences as they perceived them.

Table 3 Student activities and resources in the Parkinson project

\begin{tabular}{|c|c|c|c|c|}
\hline Student & Project activities & Curriculum resources & $\begin{array}{l}\text { Social } \\
\text { resources }\end{array}$ & General resources \\
\hline $\mathrm{D}$ & $\begin{array}{l}\text { (Mechanical } \\
\text { Engineering) }\end{array}$ & $\begin{array}{l}\text { Literature study } \\
\text { Signal processing } \\
\text { Sensor selection } \\
\text { Sensor positioning }\end{array}$ & Literature & $\begin{array}{l}\text { Databases } \\
\text { Software: Matlab, } \\
\text { Simulink, Excel }\end{array}$ \\
\hline $\begin{array}{l}\text { Authors of } \\
\text { papers } \\
\text { Staff of }\end{array}$ & $\begin{array}{l}\text { mechanical } \\
\text { engineering }\end{array}$ & $\begin{array}{l}\text { Internet, } \\
\text { YouTube }\end{array}$ & & \\
\hline $\begin{array}{l}\text { C (Data } \\
\text { science) }\end{array}$ & Programming & $\begin{array}{l}\text { Reference to university } \\
\text { courses: Programming, } \\
\text { App development, } \\
\text { Calculus, Modelling. } \\
\text { Internship data science }\end{array}$ & $\begin{array}{l}\text { Friends } \\
\text { e-lucid } \\
\text { helpdesk }\end{array}$ & $\begin{array}{l}\text { Own interests: own web } \\
\text { app development } \\
\text { company; Arduino and } \\
\text { Arduino website } \\
\text { Codeacademy.com } \\
\text { 'Instructables' }\end{array}$ \\
\hline B (Industrial & Engineering) & $\begin{array}{l}\text { Literature research } \\
\text { Sensor assessment } \\
\text { Positioning sensor and } \\
\text { gathering data } \\
\text { Processing data }\end{array}$ & $\begin{array}{l}\text { Reference } \\
\text { to }\end{array}$ & $\begin{array}{l}\text { university courses: } \\
\text { Methodology of industria } \\
\text { engineering research } \\
\text { Product innovation } \\
\text { processes } \\
\text { Engineering design } \\
\text { Scientific literature }\end{array}$ \\
\hline $\begin{array}{l}\text { Not } \\
\quad \text { indicated }^{1}\end{array}$ & Not indicated ${ }^{1}$ & & & \\
\hline
\end{tabular}

Notes: ${ }^{1}$ : Social and general resources in the SRRS of student B referred to the process of selecting a project, and not to the activities performed during the project 


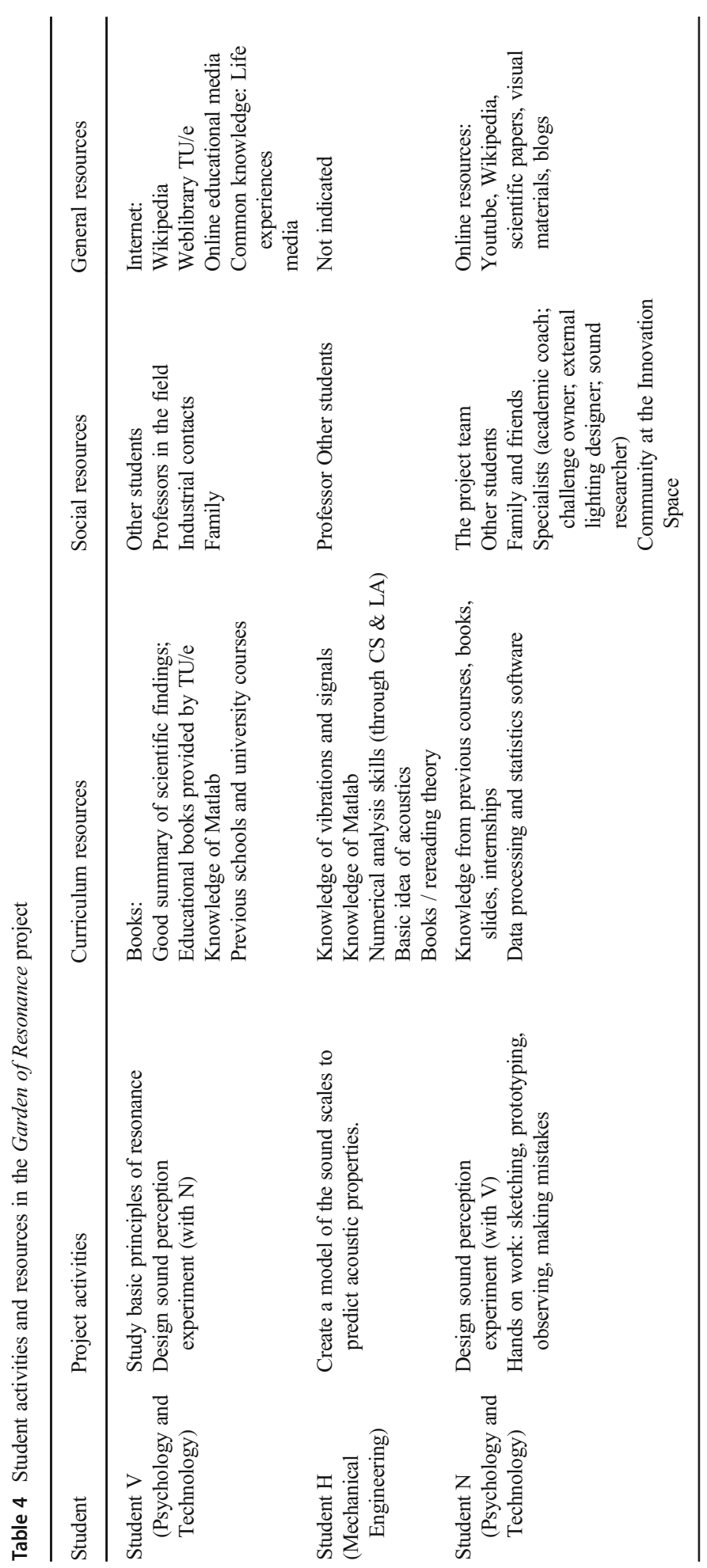


In terms of analysis, first the interviews were transcribed. Second, we selected and categorized interview quotes and the text on the SSRSs to qualitatively describe the aim and activities of the students in the projects and identify the types of resources they had used. Moreover, we selected all interview quotes with a reference to mathematics and summarized the references to mathematics in the student reports. The categories were based on the types of resources described in the literature, the types of mathematics (e.g. Calculus), the mathematical tools students referred to, and the role of mathematics for the different students. Third, student SRRSs were compared with their explanations (within case comparison): which curriculum representations they referred to; how they explained their identification of (for them) suitable resources and the orchestration of these resources; this resulted in self-reported study paths. Fourth, these self-reported study paths were compared across the focus group, and across the cases. This resulted in particular types of study paths typical for the CBBEP students. In a fifth step, the findings from this study were compared with the results from a previous study (Pepin and Kock 2019).

\section{Presentation of Results}

In this section we first present the two groups and their projects, followed by the SRRSs of selected students, their explanations on the role of mathematics in the project, and on the use and alignment of the resources.

\section{Parkinson Project}

In the Parkinson project the students focused on the so-called freeze of gait issue. During a freeze of gait episode, Parkinson patients unexpectedly feel as if their feet are stuck to the ground while they are trying to take a step. Patients have an increased risk of falling as a result of a freezing episode. Present research is directed at understanding the occurrence of these episodes. In the project, students were working on the development of a prototype sensor to detect a freeze of gait situation.

In the words of one of the students involved in the Parkinson project, the aim of their project was:

The first goal of the project is to make a wearable sensor for the patients in order for the researchers to analyse the patients. So, the main focus of our group is at first detecting freeze of gait. (Int Foc B).

The group wanted to make a prototype sensor that could easily be worn by patients and allowed continuous monitoring of the patients by researchers. But to make such a sensor, the students had to first find out how to detect a freeze of gait. And to do that they needed "a bit of mathematics or a bit of data science" (Int Foc B).

In Table 3 we have listed the student reported project activities, and the different resources used for their project work and learning.

In the CBBEP reports we could identify particular mathematical (cognitive) resources that students used. For example, student D (from the Mechanical Engineering Department) used the following mathematical concepts in his report: 
- Calculus: double integration from acceleration to displacement, based on information from the literature. Numerical integration of the acceleration sensor data was implemented in a Matlab script in which measures were taken to avoid 'integration drift'. The Matlab scripts were not part of the CBBEP report, so details of the numerical calculations could not be found.

- Basic mathematics: the students used an approach based on an inverted pendulum suggested by a scientific paper to calculate the stride length of a person walking. Mathematically, this involved Pythagoras' theorem and basic algebra. The approach was implemented by the student in a Matlab script.

- Finding maxima and minima in the data. This was implemented in Matlab scripts using a function in one of the Matlab 'toolboxes'.

- The literature overview referred to various signal processing concepts (e.g. filtering techniques). It appears these were not used in the Matlab scripts.

Moreover, in the CBBEP report of student D, a flow chart was provided, in which he explained the procedure for estimating step length. This included selected mathematical and computational skills.

As another example, student $\mathrm{C}$ (from the Industrial Design department) worked on prototypes of the sensor, as well as the collection and analysis of data coming from the sensor. In his report he described, amongst others, how he used the mathematical technique of Fast Fourier Transform to find probable freeze of gait events. The main resources he mentioned for using this technique were a scientific paper and JavaScript library functions. According to his report, an IS coach advised student $\mathrm{C}$ to be careful about the presentation of complicated mathematics to the challenge owner (a medical specialist): "Doctors do not understand Fourier transformations and time series. Your signal processing should be as easy as a LED going on and off." So, in his report, student $\mathrm{C}$ noted that "the output of this sensor system should also be readable for the researchers; they are not familiar with mathematical calculations or raw sensor data. Therefore, the sensor output has to be processed and presented in such a way as to give valuable information to the researchers."

In the interviews, the students also mentioned the importance of mathematics as a resource in the project, although mathematics was not at the heart of their engineering design:

So, we are now trying to recognize these freeze of gait moments automatically from our data, from the sensor. (...) Some calculus is in our project at this moment. (Int Foc C).

Students C and D specifically mentioned Calculus, and the techniques of double integration from an acceleration to a displacement. Moreover, the students were dealing with issues of measurement errors, the filtering of signals, and analysis in the frequency domain.

... my coach just told me that I just have to focus on obtaining the step frequency ... to know, if we can get some valuable information out of that and try to determine some freeze of gait moments. But actually, the real interesting part would be to determine the stride length. (...) And that would require the double integration of the vertical acceleration signal. (Int Foc D) 
Student D was trying to obtain characteristics such as the step frequency out of the signal by using filtering techniques, which, in his opinion was not a straightforward use of calculus, "but mainly a broad variety, maybe of calculus." (Int Foc D).

The students realized that some of their previous courses and learning experiences were useful as cognitive resources:

Like, you have calculus mathematics and modelling, those are very important basic skills for an engineer I think. ... I think for example when you want to calculate the stride length, you have to integrate. (Int Foc C)

To deal with the mathematical questions, they mastered and employed digital resources, in particular Matlab/Simulink and JavaScript. Student D explained the resources he used to obtain the knowledge needed for the project, as shown in his SRRS (Fig. 2):

Because the double integration was really a hard thing (...) I contacted a master student who helped me further with the Matlab and Simulink part. I also asked my own supervisor or tutor. I also got in contact with another faculty staff member. ... He helped me with the sensor part, and filtering signals.... And [the supervisor] helped me a little bit, but he didn't have the time to figure it out himself. So, I was all by myself and looking it up on the internet, and YouTube videos and Matlab documents and such. (Int Foc D)

In both studies it became clear that social resources had a crucial role: "If something is really getting complicated, I will always get back to people, such as my supervisor, or other people who could help me out, such as a master student." (Int Foc D). Student D needed help to mathematically process the raw sensor data, so he contacted his academic coach (supervisor) and another staff member, who could not help him, because they were not specialized in that particular type of problems. In the end the student contacted an author of a scientific paper he had used, who advised him on a suitable integration procedure. For the technical implementation, the student contacted a master student who had a lot of experience with Matlab and Simulink. Student D's approach was to "look for help where you think there's someone that can help you". (Int Foc D; see Fig. 2).

In particular, the academic coaches seemed to bring together the information for students, and on the basis of the coach's advice meaningful pathways for progressing could be found. During the interviews, one of the students explained his words with a gesture (of his arms): illustrating (with a cyclical arm swing) that he (the student) would identify, read and 'go round' all possible resources, and the coach would help him how to select by refocusing on the project's aim.

From the SRRS and interviews, we identified particular self-reported study paths. Student D (Fig. 2) put a literature study at the center of his work. He interacted with several social resources when he got stuck, including the authors of scientific papers, and knowledgeable peers. Student C (Fig. 3) built knowledge from university courses and knowledge he had developed following his own interests, using internet, literature, and social resources. 


\section{Garden of Resonance Project}

In the Garden of Resonance project, the students assisted the challenge owner, who was an artist, in creating a work of art consisting of huge sound scales, intended to make it tangible how all matter is constantly vibrating. The students attempted to model and design sound scales producing a sound spectrum with frequencies that had a calming effect on the listener.

One of the students (student V) described the aim of the project in the following way:

We decided that we wanted to have an experiment that looked at the different attributes of sound. So, we found that sound is made out of, or sound perception, actually, is made out of different attributes, so, intensity, frequency, length, gap, complexity. And these attributes together are how we perceive the sound. So, we were thinking that if you can tune the attributes in such a way that you can induce a certain sound that you want. So, the feeling of tranquillity that we want. (Int Foc V)

Table 4 shows the project activities (as the students reported on it), and the different resources used for their project work and learning: curriculum resources, social resources, and general resources they mentioned in the interview.

In this project the roles students assigned to each other were clearly delineated, and students searched for ways of solving their particular tasks. In the case of student $\mathrm{H}$, his task was finite element modelling of the sound scales in order to predict the sound it would produce. He considered this challenging:

I'm busy with using finite element modelling, in order to approach the different model frequencies. So, the modes in which different objects move. So, I am then trying to find a way in order to translate that into a sound. So, in order to do that you need to model a bit, or estimate a bit the behavior of the soundwaves around the plate, or the disc, or the bowl, or whatever. And in order to do such, you have to do quite a bit of calculations. And I'm now busy trying to figure out how to perform that and what is the most efficient way of doing so. Because in the end what we want is that we want to obtain a desired frequency, a desired frequency tuning of one scale. (...) For my courses I had like an introduction in signals. So, the variation of one major signal is one summation of all types of smaller signals, and into vibrations. But those vibrations were mostly limited to two-dimensional parts. So, that meant that I needed to obtain knowledge about three dimensional vibrations and acoustics and the like. I especially needed to learn what not to use, and what to use. Because that is a bit of the one step forwards, two steps back program. (Int Foc H)

Digital mathematics resources, such as Matlab and its signal processing 'toolbox' (e.g. Fast Fourier Transform), were important for the students to model the problem and analyze their data.

In the interviews, students mentioned the importance of what they had learnt earlier as resources for the project. In each step of the process they tried to refer to content from previous courses and from their textbooks, and tried to apply that in the project. 
Student $\mathrm{V}$ helped students $\mathrm{H}$ to perform calculations for the model. In his view he could not have done that without mathematical knowledge drawn from previous courses.

However, they also criticized learning mathematics in traditional courses. Students $\mathrm{H}$ said he perceived the knowledge in traditional courses as knowledge that wasn't useful for him at the time. So, he just used it to pass the test and then forgot the knowledge. He would have preferred tests in which he needed to use the knowledge he had obtained "to model or make something". In the CB project he had to sit down with others, to decide what steps he needed to take in the project and then "to sketch out what information you might want to research on that" (Int Foc H), that is, what knowledge was required to complete those steps. Students expressed that they wished to be provided with "ways of finding where you get the information you need". Instead of being handed information which at that moment might be without relevance, but which might be needed at a later stage, they considered that "maybe it should be the other way around" (Int Foc V): having access, and learn particular content at the time when it is relevant and needed.

The students of this project clearly appreciated the support of the following social resources:

(a) Their peers. Another student in IS might just know a little more about modelling, and "maybe just [to] talk about it with somebody already helps in defining it a little bit more for yourself." (Int Foc V)

(b) Professors at the different departments. They know the current research and the relevant topics, "so, the professor saves you a lot of time in doing the web searching, actually." (Int Foc V). Student H's professor several times gave feedback on his work, which give rise to several learning cycles ("And then I go back again, get up and do it again.” Int Foc H; see also fig. 4).

(c) The challenge owner (artist) who originated the project. He was "really into the art world" (Int Foc V) and could, for example, indicate ideas that had already been tried before.

(d) Family. For example, student V's brother was also a student at a technical university and could occasionally advise him.

The social resources were also evident in students' SRRSs (Figs. 4 and 5).

In terms of student study paths, we observed that student H (Fig. 4) described a cyclic path of developing knowledge using different material and social resources, subsequently being corrected by feedback from the professor who was his academic coach, after which the process of knowledge development started again (while "slowly getting more courage again"). During the interview student $\mathrm{H}$ showed this process by opening his arms 'wide', and then pulling the two hands together indicating the focusing (by the tutor). Student N (Fig. 5) drew his SRRS with categories of resources he had used, but without a specific sequence.

\section{Mathematics resources in students' work}

All students referred to categories of resources, including mathematics resources, containing curriculum materials from the university, but also social resources from within and outside the university, plus a range of general resources, often web-based. 
Digital software, such as Matlab, were important resources for students D and H to shape their mathematical practice and to help develop a solution to the challenge, based on the mathematical concepts involved. These resources provided access to mathematical calculations and techniques as a 'black box'. For example, numerical integration and Fast Fourier Transform algorithms were provided as standard functions in the software; in other words, using these resources the students did not need to be involved with complicated mathematical procedures and calculations. However, from the data it has become clear that the students needed a good conceptual understanding and some detailed knowledge of the mathematics to be able to use the resource sensibly. For example, student $\mathrm{D}$ was provided with acceleration data from a sensor, but was interested in estimating a displacement (stride length of a person). The student's report shows that he started with a basic mathematical model from the literature, which he adapted to take-into-account the particulars of the sensor used in his project. This involved a range of mathematical calculations, including a double integration of processed sensor data (see Fig. 1). Deciding on the starting value of each integral was not a trivial task for the student, due to the iterative nature of the strides. After solving these issues, he implemented the calculations as a Matlab script (not provided in the report). There is no evidence that the student learned new mathematical concepts and techniques during his CBBEP. However, the interviews and report show that he struggled, and then came to grips, with the translation and use of the standard mathematical procedures from Calculus courses to model a complicated real-life situation. In other words: the mathematics came to life for this student. During the interviews, students D and other students referred to previous mathematics courses, such as Calculus, but remarked that these did not align very well with their tasks in the projects.

\section{Discussion and Conclusions}

The findings show that in the CBBEPs students used resources outside the realm of curriculum resources offered to them in traditional courses. These included different

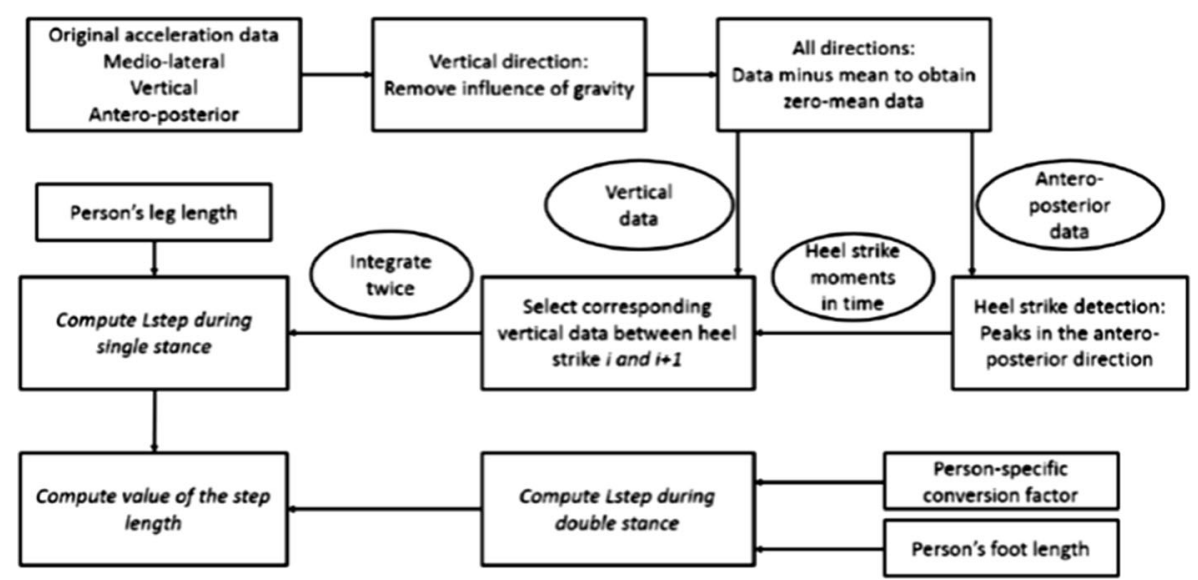

Fig. 1 Student D. Flow chart showing the procedure for estimating the step length 


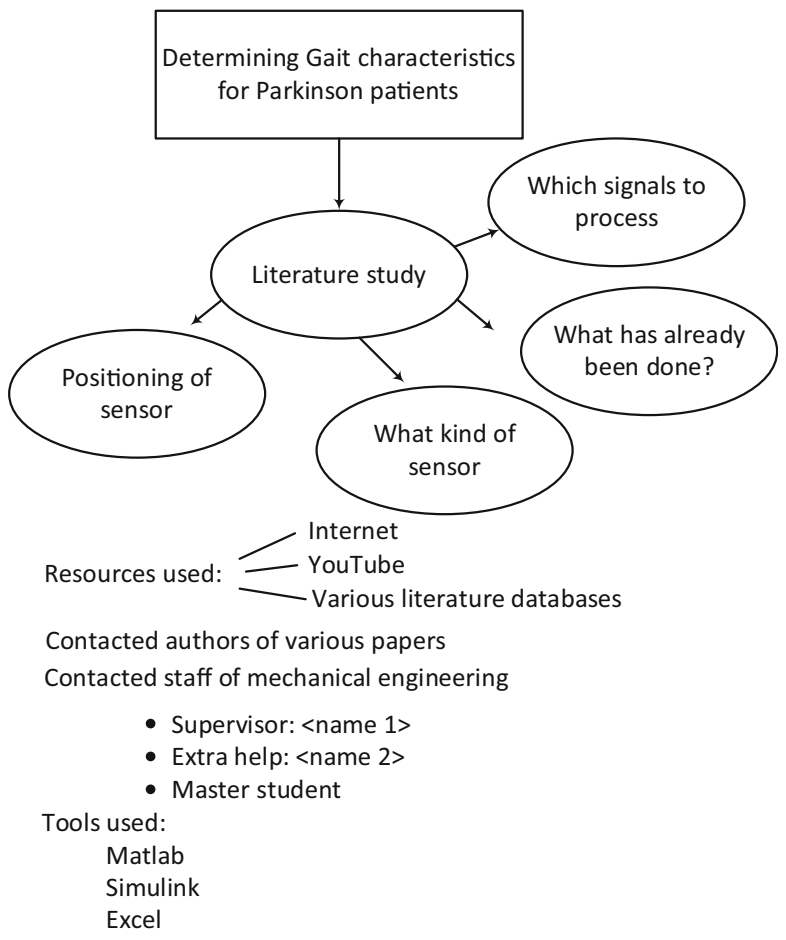

Fig. 2 Student D SRRS (Transcribed from original drawing for readability)

Basis:

Courses: Programming, app development, etc. Basic courses (Calculus, modelling) Internship (Data Science at PSV Eindhoven)

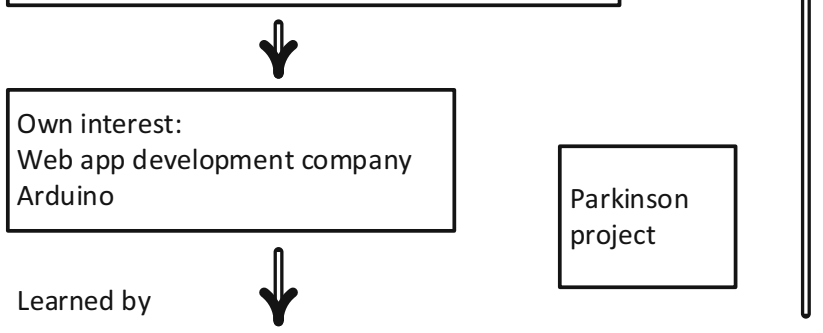

Codeacademy.com
Arduino website
Instructables
Friends
E-lucid helpdesk
Self-directed learning

Applying to project

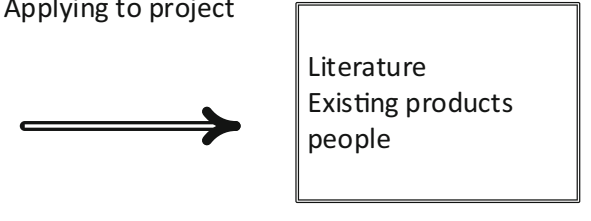

Fig. 3 Student C SRRS (Transcribed from original drawing for readability) 


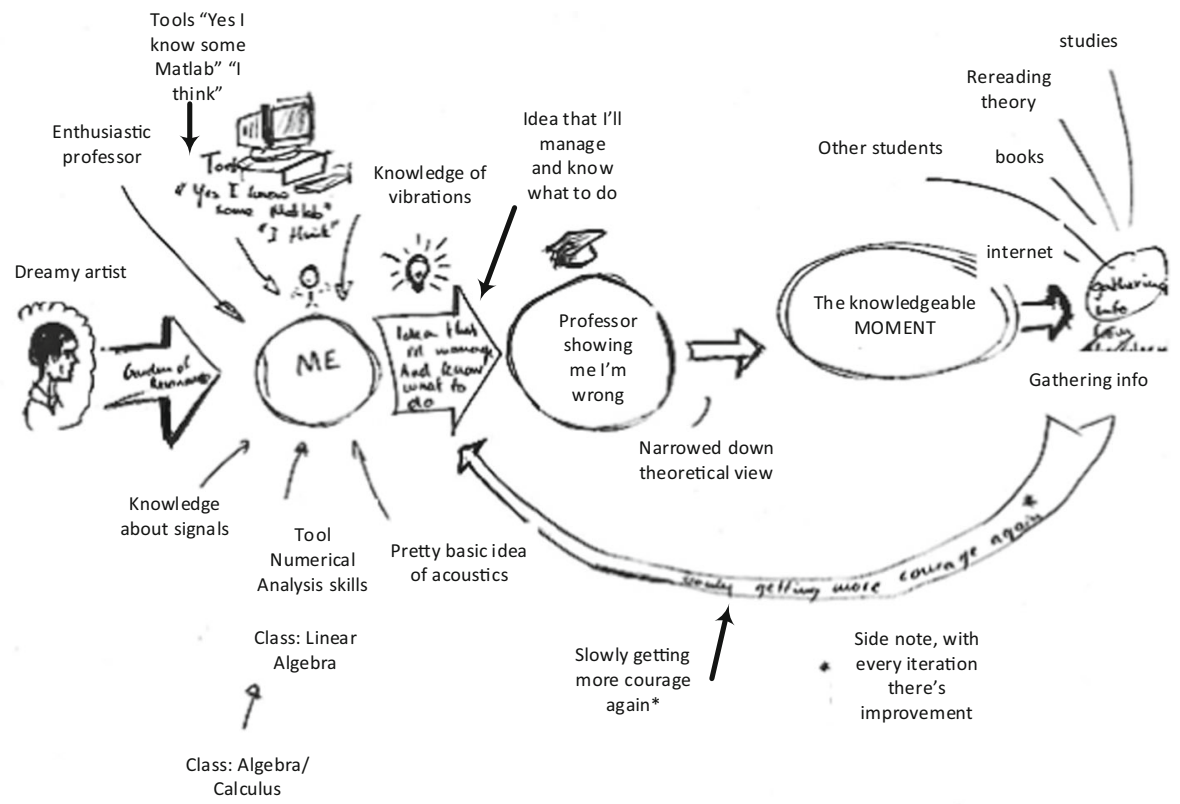

Fig. 4 Student H's SRRS (Transcribed from original drawing for readability)

'pieces of knowledge', scientific papers, software, peers and experts in the field. In particular, social resources took on a special role, and the most prominent was the role of the coaches: they gave discipline-specific advice and helped students to re-focus on

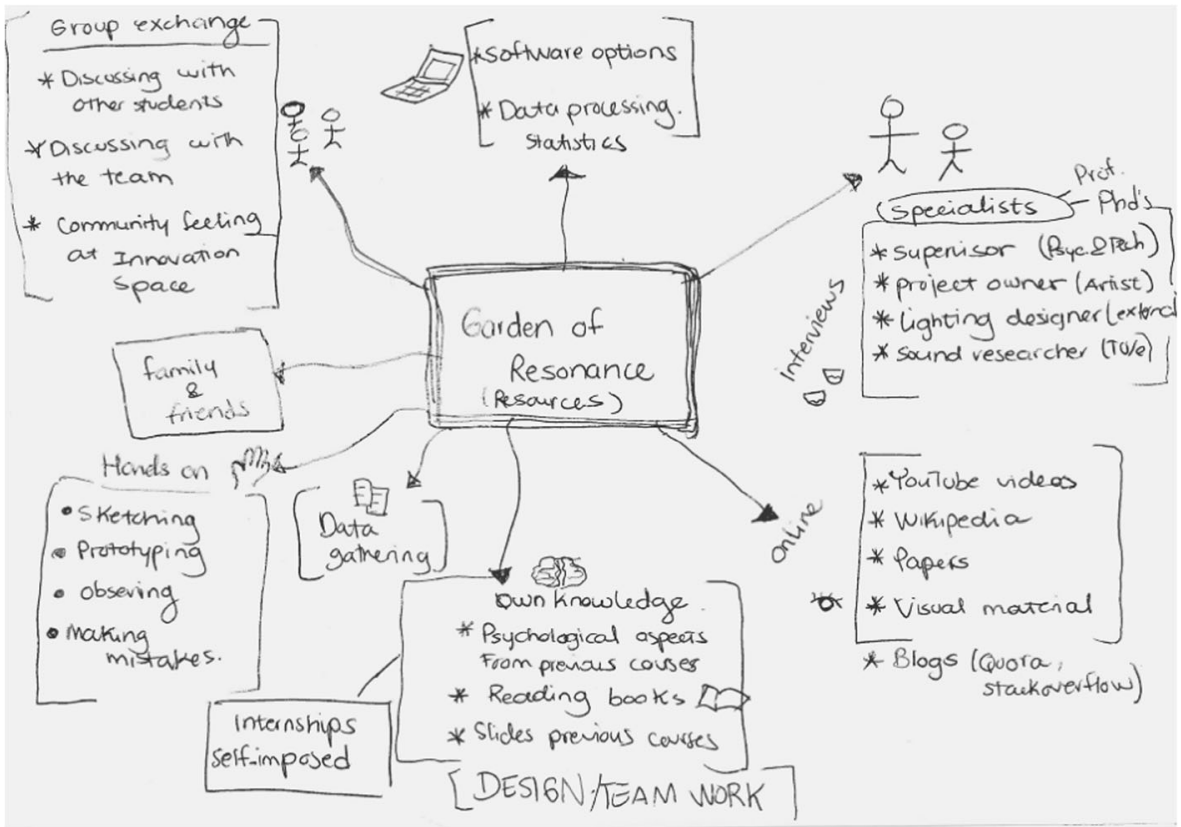

Fig. 5 Student N SRRS 
the project aims, when the students' ideas went into different directions in an attempt to find solutions to their individual problems.

In a previous study (Pepin and Kock 2019) we used a similar case study approach to investigate 24 students' orchestration of resources in first year Calculus and Linear Algebra courses in the same engineering university. Comparing the structure of the Calculus and Linear Algebra courses with those of the CBBEP course, they were of different kinds: (a) In the Calculus and Linear Algebra courses a number of curriculum resources were suggested by the course leaders, and in the case of the Linear Algebra course the learning path and the resources were well-defined and aligned. (b) In the CBBEP projects, the students were not given resources to pick from, there were no predefined resources, and no pre-determined learning paths. The multi-disciplinary groups of students had to find their own ways of defining and solving the problems within the open challenges posed by the stakeholders, and it appeared that they very much depended on guidance by social resources (e.g., tutors). For their guidance, the students had the IS coach and tutor, their individual academic coach, and some guidance from the challenge owner. From the interviews, the SRRSs and student reports it became evident that students also reflected on and used their previously learned knowledge and experiences, within or outside the university, in order to solve the problem at hand (e.g. experience gained during an internship at the local football club, on data processing in the $\mathrm{CB}$ project).

In terms of ASSPs, they were typically iterative or cyclical: focused on the common project goal, 'diverging' when working in the group, and 'converging' with the help of the tutor providing focused advice. There were differences and similarities between the CB project study paths, and those of the traditional Calculus and Linear Algebra courses (Pepin and Kock 2019). If put on a continuum between linear to non-linear (e.g. cyclical) study paths, we argued that the LA course related paths appeared to be mainly linear and sequential, possibly due to the learning trajectory as designed by the course leader. The ASSPs related to the Calculus course were mainly examination and test driven, and students' SRRS often had the test or a particular resource at its center (e.g. the lecture, or peers). In contrast, the CBBEP related paths were cyclic, with divergent and convergent phases: the students gathered knowledge about how they could define and solve the CB problem, which was often going rather wide, only to be refocused by one of the tutors or the challenge owner. These iterative cycles of 'diverging' and 'converging' (in terms of focusing) seemed to be illustrative of the study paths in the CBBEP projects. Some students described, and drew their SRRS as a flow, with the resources being connected in an order in which they were accessed. Others described it as groups of resources, connected to a common theme, starting point or core. Nevertheless, in the interviews it became clear that their study paths were also revisiting the different types of resources in an iterative or spiraling way (whilst going deeper into their problem area). No student talked about, or drew, a linear study path.

Some students mentioned the importance of the basic mathematics courses as cognitive resources, and they valued the knowledge they had obtained now that they were using mathematics as a resource in their projects (Rasmussen and Kwon 2007). It appeared that the traditional 'linear' ASSPs had their benefits in terms of students developing confidence with particular mathematical concepts (e.g. of Calculus or Linear Algebra). However, the cyclical CBBEP ASSPs show that students needed guidance for developing confidence when dealing with uncertainties (e.g. which mathematics resources to use for the benefit of solving the $\mathrm{CB}$ problem) in a 
multidisciplinary group, and they acquired this confidence with the tutor, and to some extent with their peers.

It is clear that the $\mathrm{CB}$ project learning environment has changed the roles of both the teacher and tutors, and of the students. For the students, the emphasis was on coping with the new situation of developing into a self-regulated learner in a multidisciplinary group of peers. Their roles changed from that of the learner who is provided with knowledge to be processed in various situations, to that of the co-designer of the problem who has to identify and use suitable resources for the solution of the problem at hand. The teacher's role changed, from the traditional discipline-specific teacher role, to that of a coach, who had to foster learning by providing feedback and advice. This was due to the open-endedness of the challenges, which included knowledge of several disciplines and flexibility in tutoring students with different disciplinary backgrounds.

The central role of the tutor and coach in the CB learning environments has implications for competences required of university teachers: they would need to be able to guide students in these complex and open-ended projects, need to be proficient in fostering learning through feedback, and need to be able to take a more process-oriented perspective, rather than a purely discipline-oriented perspective. It also has implications for the education of students who opt for such courses or projects: students have to be supported by CB education trained coaches and teachers, and learn to identify and use suitable curricular, technological, and social resources. Students may then develop as self-determined, sociably open-minded, and mathematically-knowledgeable engineers, who are willing and able to solve grand engineering challenges.

More generally, we claim that the focus on students' use of resources helped us to develop a deeper understanding of the support students need when the curriculum changes from a teacher-centered to a student-centered one. When the CB education approach becomes more widely enacted at the university, a next step in our research will be to investigate student learning trajectories and to measure learning outcomes in CB education experiments with larger numbers of students, such as first-year Calculus courses. Demonstrating beneficial effects at scale is challenging due to the complexity of the inter-dependencies of the constituent parts of students' learning trajectories (and ASSPs) that are deeply embedded in the teaching-learning settings. However, it is important to investigate how learning can be strengthened and students can be assisted in moving along different interwoven pathways in open-ended challenges. In this study, we gained some understanding of the ways in which study paths may unfold in CB education. With a growing understanding of these paths, we conjecture that it may be possible to identify and design suitable paths and trajectories in a CB curriculum (e.g. for Calculus). Then, they can be detailed and articulated so as to foster student learning of the content. A CB education at scale demands systemic change at the university, and demonstrating positive student outcomes will be a gradual process requiring widespread commitments (e.g. from teachers, education directors, deans), extensive IT support for providing the necessary resources, and broad policy supports.

Acknowledgements The authors would like to thank the Bachelor College and Graduate School at Eindhoven University of Technology for funding this study. 
Open Access This article is licensed under a Creative Commons Attribution 4.0 International License, which permits use, sharing, adaptation, distribution and reproduction in any medium or format, as long as you give appropriate credit to the original author(s) and the source, provide a link to the Creative Commons licence, and indicate if changes were made. The images or other third party material in this article are included in the article's Creative Commons licence, unless indicated otherwise in a credit line to the material. If material is not included in the article's Creative Commons licence and your intended use is not permitted by statutory regulation or exceeds the permitted use, you will need to obtain permission directly from the copyright holder. To view a copy of this licence, visit http://creativecommons.org/licenses/by/4.0/.

\section{References}

Anastasakis, M., Robinson, C. L., \& Lerman, S. (2017). Links between students' goals and their choice of educational resources in undergraduate mathematics. Teaching Mathematics and Its Applications, 36, 6780.

Ausubel, D. (1963). The psychology of meaningful verbal learning. New York: Grune \& Stratton.

Biza, I., Giraldo, V., Hochmuth, R., Khakbaz, A., \& Rasmussen, C. (2016). Research on teaching and learning mathematics at the tertiary level: State-of-the-art and looking ahead. ICME-13 Topical Surveys, Springer International Publishing AG Switzerland. https://doi.org/10.1007/978-3-319-41814-8_1.

Case, J., \& Marshall, D. (2004). Between deep and surface: Procedural approaches to learning in engineering education contexts. Case Studies in Higher Education, 29(5), 605-616.

Dahl, B. (2018). What is the problem in problem-based learning in higher education mathematics. European Journal of Engineering Education, 43(1), 112-125. https://doi.org/10.1080/03043797.2017.1320354.

Deane, P., Sabatini, J., O'Reilly, T. (2013). The CBAL English language arts (ELA) competency model and provisional learning progressions. Retrieved from http://elalp.cbalwiki.ets.org/Outline+of+Provisional+ Learning+Progressions

Deans Bachelor College and Graduate School. (2020). TU/e education 2030: Drivers of change. Eindhoven: Eindhoven University of Technology.

Enelund, M., Knutson Wedel, M., Lundqvist, U., \& Malmqvist, J. (2013). Integration of education for sustainable development in the mechanical engineering curriculum. Australasian Journal of Engineering Education, 19(1), 51-62.

Graf, E. A., \& van Rijn, P. W. (2016). Learning progressions as a guide for design: Recommendations based on observations from a mathematics assessment. In S. Lane, M. R. Raymond, \& T. M. Haladyna (Eds.), Handbook of test development (2nd ed., pp. 165-189). New York: Taylor and Francis.

Gryszkiewicz, L., Lykourentzou, I., \& Toivonen, T. (2016). Innovation labs: Leveraging openness for radical innovation? Journal of Innovation Management, 4(4), 68-97.

Gueudet, G., \& Pepin, B. (2018). Didactic contract at the beginning of university: A focus on resources and their use. International Journal of Research in Undergraduate Mathematics Education, 4, 56-73. https:// doi.org/10.1007/s40753-018-0069-6.

Hassan, Z. (2014). The social labs revolution: A new approach to solving our most complex challenges. London: Berrett- Koehler.

Inglis, M., Palipana, A., Trenholm, S., \& Ward, J. (2011). Individual differences in students' use of optional learning resources. Journal of Computer Assisted Learning, 27, 490-502.

Lehrer, R., \& Schauble, L. (2015). Learning progressions: The whole world is not a stage. Science Education, 99(3), 432-437.

Malmqvist, J., Rådberg, K. K., \& Lundqvist, U. (2015). Comparative analysis of challenge-based learning experiences. In CDIO (Ed.), roceedings of the 11th International CDIO Conference. Chengdu: Chengdu University of Information Technology.

National Academy of Engineering. (2017). NAE grand challenges for engineering. Washington DC: National Academy of Sciences.

Pepin, B., \& Gueudet, G. (2014). Curricular resources and textbooks. In S. Lerman (Ed.), Encyclopedia of mathematics education. Berlin: Springer.

Pepin, B., \& Gueudet, G. (2018). Curriculum resources and textbooks in mathematics education. In S. Lerman (Ed.), Encyclopedia of mathematics education. Cham: Springer.

Pepin, B., \& Kock, Z.-J. (2019). Towards a better understanding of engineering students' use and orchestration of resources: Actual student study paths. In U. T. Jankvist, M. van den Heuvel-Panhuizen, \& M. Veldhuis (Eds.), Proceedings of the Eleventh Congress of the European Society for Research in 
Mathematics Education. Utrecht: Freudenthal Group \& Freudenthal Institute, Utrecht University and ERME.

Pepin, B., Choppin, J., Ruthven, K., \& Sinclair, N. (2017a). Digital curriculum resources in mathematics education: Foundations for change. ZDM- Mathematics Education, 49(5), 645-661.

Pepin, B., Xu, B., Trouche, L., \& Wang, C. (2017b). Developing a deeper understanding of mathematics teaching expertise: An examination of three Chinese mathematics teachers' resource systems as windows into their work and expertise. Educational Studies in Mathematics, 94(3), 257-274. https://doi.org/10. 1007/s10649-016-9727-2.

Rasmussen, C., \& Kwon, O. (2007). An inquiry-oriented approach to undergraduate mathematics. Journal of Mathematical Behavior, 26, 189-194.

Simon, M. A. (1995). Reconstructing mathematics pedagogy from a constructivist perspective. Journal for Research in Mathematics Education, 26, 114-145.

Simon, M. A., \& Tzur, R. (2004). Explicating the role of mathematical tasks in conceptual learning: An elaboration of the hypothetical learning trajectory. Mathematical Thinking \& Learning, 6(2), 91-104.

Thijs, A., \& Van den Akker, J. (2009). Curriculum in development. Enschede: SLO.

Publisher's Note Springer Nature remains neutral with regard to jurisdictional claims in published maps and institutional affiliations. 